\title{
Cultural Determinants of Depression: An ethnographic perspective about mental health
}

\author{
1. Imtiaz Ali Seelro (M.Phil.) \\ Lecturer (Medical Anthropology) Institute of Public health \\ People's Medical University of Health Science, Shaheed Benazirabad, Sindh Pakistan
}

2. Abdul Razaque Channa (PhD)

Assistant Professor, Department of Anthropology and Archaeology,

University of Sindh, Jamshoro

3. Inamullah Leghari (PhD)

Assistant Professor, Department of Anthropology,

Quaid-i-Azam University, Islamabad)

\begin{abstract}
This article is about cultural determinants of depression. The article explores relationship between cultural patterns and psycho-social factors causing depression among people living in a small rural village of Mir Karam Ali Khan Mangal district Kamber-Shahdadkot northern Sindh Pakistan. Current research also aims to investigate the local's point of view about health, wellbeing, illness, and depression.

Qualitative methods were employed to conduct the research for understanding cultural nuances of depression as culture and health cannot be studied in isolation. Health system of any society is innately associated with the cultural ethos and practices.

Consequently, culture plays a significant role in shaping and developing overall health of an individual and society. There are few important factors such as family conflicts, change of moral values, famishment of wealth and economic hardships which are important cultural determinants of depression in selected research locale. The study has observed how cultural or social factors, one way or another, become the cause of depression.
\end{abstract}

Keywords: Culture, Depression, Health, Economic, Family

Article Received: 10 August 2020, Revised: 25 October 2020, Accepted: 18 November 2020

\section{Introduction}

Internal and external body environments are interconnected in many ways that impact each other in a two-way relationship. Human cognition and physical culture are the most significant element in this connection, which influences cultural life structures of people living across the world. Human beings face different experiences in life cycles, however few experiences lead to depression among people if they remain problematic for a longer period (Winkelman, 2009, p. 38). The term 'Heath' connotes different meanings and understanding with relation to different cultures, where the practitioners, physicians and social psychologists define the term per their own understanding and experience. Health is defined as a person with both physical as well as social well-being. However, social well-being is an integral part of the culture (Hofgastein, 2011, p.1).

Depression is found one of the frequent diseases across the world. More than 300 million people are affected every year. However, it is unlike from common mood variation or short-lived behavior responses in day today life of people being a member of society. At its worst level, the disease results to suicide. Close to 800000 individuals die because of suicide every year. Depression is known as the second key variable of death in 15-29 years old (WHO, 2018, para, 2). Globally, the depression and other mental disease has increased dramatically. Severe depressive disorders are considered as common mental illness, with a lifetime occurrence of $15.8 \%$. Severe depressive disorders cause substantial personal suffering and it decrease functioning in day-today activities and is a known leading cause of suicide among people. Individuals who are depressed have reported to have reduced life enjoyment and spend less quality life. Those people do not perform well in their academic performance and adversely affect productive work and social relationships. Depression is one of the leading illness towards worldwide disability and societal burden. Intensity of depression varies considerably, it can vary from 
minor symptoms to sever, long-lasting and devastating symptoms, effects every share of life of people (Haran, 2009, p. 269-73). In Global South, depressive disorders are serious health concern and are expected to become common factor causing disability by 2020(see for example WHO and World Bank,1996). Possible contributing factors may include such as poverty, poor facilities of education and health, cultural attitudes about depression, and exposure to infectious disease or illness (see for example Hollifield et al. 1990; Abas \& Broadhead, 1997).

In current times, depression and mental health disorders have become very common diseases, especially in troubled war zones or in the areas where people are forced to live in severe economic, social, and environmental conditions. Meanwhile, a continuous encounter with such situations creates severe mental disorders that cause anxiety and depressive ailments. In its severe forms, the victims may end up their life, committing suicides, and mainly seeking ultimate refuge from stressful situations. Meanwhile, the physical and mental health of an individual is linked to the culture and income patterns of people. In a circular relationship, people derive their welfare and happiness from their surrounding or immediate environment like workplaces, family environments and communal life, where people spend most of their lifetimes.

Economic downturn, stress and depression has an impact to increase disease such as cardiac failure, kidney diseases, strokes, infant mortality and mental illness. Economic deprivation enhances depression and results in intensified struggle for the necessities of life. Similarly, economic stress has socio-psychological and physiological impacts which result in increased mortality rates. Preventing disease and promoting health requires special attention for social factors and environment conditions that increase exposure towards the risk medium. In contrast to this, economic depressive disorders lead an individual to a much more immediate mortality rate and have increased mental illness (Winkelman, 2009).

\section{Literature review}

Sigmund Freud and Karl Abraham explain depression as a complicated response against the loss of important individual or other loved thing. Such loss can be actual or imagined by death of an individual, separation, or refusal. Those people who are at risk to depression behave uncertainty to other people. They may be positive or negative and over taking other's expression of feelings. Such experience of those people is a result of early and repeated disappointments. According to Freud, depressive disorders are known as grief out of control. Beside this, depressed people are more self-destructive and are not confident to do day to day targets. Similarly, agitation and unhappiness that was caused by lose of loved one or things are adopted which usually leads to lack of self-esteem. Many theorists who had applied same approach and modified Freud's ideas are known as Melanie Klein, SandotRado and John Bowlby (Borgatta\& Montgomery, 2000, p. 649). The concept of disappointment, unhappiness, agitation and separation of loved once are studied in relationship of culture and mental health. Current research examined the relationship of culture and depression that how culture influence once habits and expected behavior in specific conditions as a member of society.

Depression is known as one of the major widespread diseases in the United States and Western countries. According to one medical survey, one third of the population in the United States are suffering from lifetime depression. In some cases, people who are diagnosed with depression do not pay visit to trained practitioner, instead they take antidepressant. It is estimated that antidepressants will exceed antihypertensive as to be prescribed class of drugs in the United States. Apart from being the signature diagnosis of contemporary psychiatry, depression has become such an encompassing lay category for unhappiness that normal sadness is said to be lost in the United States (Kleinman, 2009, p. 177). This study explores cusses of persistence of depressive disorders among people in the village. Beside this, the study analyses health awareness and education and health care facilities in the village.

Research related to health and risk of disease highlight the effects of culture change and the cultural effects of transformation, or the transition of societies from mainly agricultural to modern and industrial society. Major cause of depression is social and psychological factors that have long been suspected (Erickson \& Singer, 2011 p. 120).

There are some major sources of marginalization that increase the risk for common depression disorder. These common depressive disorders are as economic marginalization, gender discrimination, social anxieties, migration, or displacement and physical or bodily discomfort etc. People of low socio-economic status had higher odds of being depressed. Beside this, high levels of class difference may also lead to high risk of economic depression. (Kleinman, 2011, p. 286). Life style is one of the major variable for conducting any research related to culture and health. The current research investigates that how culture plays an important role in shaping health of an individual living in the society. Further, how shifting economic and moral life of people have 
asserted adverse impact on people are major dynamics of the research.

There are some major economic variables in the study of mental health which can lead an individual to common mental disorder.Economic deprived people are most vulnerable people in society to experience depression. Moreover, economic instability is directly proportional to experience depressive disorders by people. Moreover, life compels us to encounter different life events, as a result some are good and other are bad which become hard to accept in once life. For instance, accidents, or sudden death of someone beloved leads to stress and depression (Rumberger et al., 1990 , p.76).Current paper attempts to analyze the relationship of uncertainty of economic status, culture and depressive disorders in the village. Beside this, current paper examines different depressive life experiences of people being member of the village.

\section{Methods}

There are two main approaches, positivistic approach and the interpretive-phenomenological approach which are used to study the human sciences (Bernard, 2006, p. 24). Current research has adopted a positivistic approach. This study is designed on the bases of inductive methods. Moreover, qualitative methods are employed for data collection. Subsequently, different research tools and techniques are applied on different stages and phases on merit base for data collection by researchers. For instance, rapport building, key informant, participant observation, informal interviewing, unstructured interviews, focus group discussion, purposive sampling, socioeconomic, census survey form are some of the techniques employed in the field for data collection.

The study has selected respondents from different classes and categories like sex, age, ethnic identities. People who have direct or indirect experience of depressive disorder were selected for interviews. However, purposive sampling techniques was used for accessing the targeted respondents. Purposive sampling was used for three purposes. A) Informants were selected who have experienced depressive disorder. B) respondents who were immediate family members of people who experienced depressive disorders. C) people who were engaged in diagnosing and counselling depressive disorder.

Table No 1: Sample size

\begin{tabular}{|l|l|l|}
\hline Age group (in years) & Selected respondents & \multicolumn{2}{l|}{} \\
\cline { 2 - 3 } & Male & Female \\
\hline $10-20$ & 5 & Nil \\
\hline $21-30$ & 10 & 2 \\
\hline $31-40$ & 5 & 1 \\
\hline $41-50$ & 3 & 1 \\
\hline $51-60$ & 2 & 1 \\
\hline $61-70$ & 1 & Nil \\
\hline & Total=26 & Total=5 \\
\hline
\end{tabular}

(Source: Field data, 2020)

Current research followed ethical considerations and obligations, protected participant'sprivacy, and anonymity. The study also obtained consent of participants about this research's aims and objectives. The study got approval from the Advanced Study and ResearchBoard (AS\&RB) of QAU, Islamabad.Beside this, current research adopted thematicalanalysis of the data during the research.

\section{Research locale}

Village Mir Karam Ali Khan Birohiis located in Taluka Qubo Saeed Khan district KamberShahdadkot, Sindh Pakistan. It is at the distance of
$491.8 \mathrm{~km}$ from Karachi to the north side of the province. As per local narratives, the name-history of the village is not exceptional and different one. In Sindh, names of towns are famous for naminghistories related to cities, towns and villages associated with famous people or events. For instance, Jacobabad, TandoAadam, Dera Jamal, Tando Mohammad Khan etc. Basically, these names are associated with influential persons which belongs tospecific cities and towns of such regions.

Mir Karam Khan Mangal 


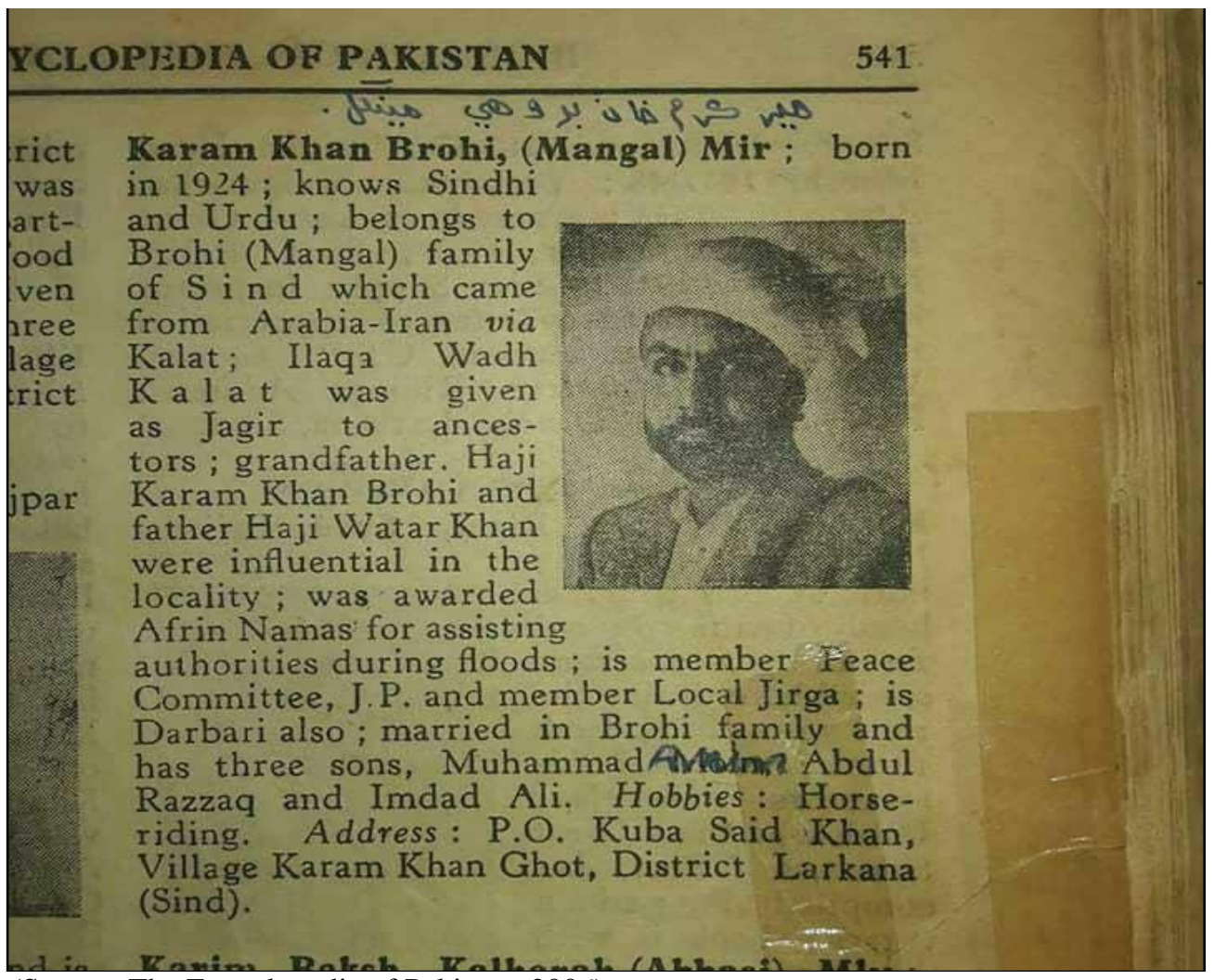

(Source: The Encyclopedia of Pakistan, 2006)

People living in the village are dependent on agriculture for economic survival. Wheat, rice, and different vegetables are major crops of the village. Agriculture of the village is seasonal, therefore in non-season people face severe economic hardship. Consequently, people living if the village compromise many enjoyable moments in search of earning money to meet the economic demands of the family.

Health facilities in the village are vulnerable, though there is one Taluka government hospital and a few private clinics, yet these hospitals are outdated in terms of health facilities and trained health care practitioners or providers. The village has alarming conditions regarding health care services facilities. Most of the private clinics in the village are run by dispensers which are not certified medical doctors or health care providers. Usually, they gain experience of 2 to 4 years of assistant of MBBS doctors in urban settings and thereafter they open their independent clinics. Their aim is to have extra benefit.

\section{Results and Discussion}

Cultural concepts are basic in understanding of health and medicine, as health behavioris interrelated to culture and vice-versa. The learned and shared behavior are important domains in understanding and explaining the characteristic of an individual being as member of culture and society. It is necessary to have cultural knowledge for advocating public health mandates as to know the community's health needs, develop appropriate health policies and ensure culturally competent health services. It is the shared responsibility of health care providers including public health officials and other actors to create health education. It is only possible when health care practitioners understand cultural systems, beliefs, and practices (Winkleman, 2009 p. 39).

According to one of the key informants, "Health is typically something which we take for granted unless it results in complications. After that the patients are likely to refer to a medical practitioner in a ray of hope for the treatment". However, the discussion raises key questions related to cultural construction and conceptualization of depression in the village. Depression is a common problem in every society and culture. However, persistent depression for a longer time period results in severe mental health disorder. For instance, isolation, loneliness, are the result of persistent depressive disorder for a longer time period. This condition leads an individual to not actively play his or her role in day-to-day activities and sometimes it leads to suicide as well. Other key informant added that, "on-going conflict either in between family members or among different families or between two or more than two tribes, or clans is one of the major causes of depression which ultimately result in the episodic inculcation of stress and depression at communal level in the village. People living in the village fight for one or other reasons, for instance people fight for achieving social prestige and symbol of braveness, some people are 
indulging in fighting due to old family rivalry. These are some of the major cultural determinants of depression found in the village. Subsequently, above-described determinants along with other cultural determinants posing continuous threat to the social and physical equilibrium of life in the village.

\section{Family conflicts}

A family's hereditary contribution to health is intermediated through socialization and environmental effects. Family is the framework in which the sick role is learned and basic care is provided. Family relationships are a vital source of motivation and support if managed and handled properly. Social status and role of an individual are important parts of any society. According to one of the research key informant, "socioeconomic status along with family identification of people signifies a person's position in the village. Another important factor for identification of position prestige in the society is achievement of an individual. Similarly, education, employment, occupation, income, or wealth are some of the major parameters of social prestige. However, social status in turn is the position within the cultural pattern, which is connected to a set of rights and duties. Unsettled family relationships and their structure are major threats for creating depression among people. However, one is supposed to fulfil all demands and expectations of his or her family. If one is not able to meet the draw-line or fixed boundaries of family expectation, then he or she must face hardships in terms of balanced relationships. Further, if a person does not come up with the expectations for one or other reason, he or she has more chances to feel depressed.

According to research findings, it is the conflict or other nature of fighting which creates problems for an individual to meet the expectations of the family. One aged and experienced informant said that, "some decades before, the concept of depression was alien discourse for people. Whereas, today people have become used to living with depression for one or other reason. He further added that instead to enjoy the social, religious and economic differences people have learned to hate the differences. In the past, people were used to arrange gatherings on regular bases for different social activities like arranging tournaments of local games, and celebrating different religious cultural occasions. Such gatherings were a symbol of enjoying harmony, prosperity, and success. It has been observed that change in moral life has drastically left impacts in people's physical, social and psychological health and well-being. They have lost the art to be happy and enjoy differences.

\section{Property inheritance and change of moral life}

Property inheritance is becoming one of the major causes of depression if not solved properly in specific time and space. According to one of the key informants, "The main cause of conflicts in the village are three $\mathrm{Z}$ which are Zan(Women),Zar(wealth) and Zameen(land) in traditional village settings. Family conflict occurs due to unfair and unbalanced division of inheritance of property to corresponded offspring. Similarly, it is a persistent factor of depression, which sometimes leads to separation of family members and turns family members to tribal conflict. He further added that property division is an important cause of depression, sometimes due to inappropriate division of inherited property and other economic resources that lead to social conflict. Consequently, people of the village lost many opportunities to enjoy and share social, moral, and economic lives in the village". According to other key informants, "a few decades ago moral and ethical dynamics of society were not the same as people understand and practice them today. People were respectful to one another and enjoyed economic, social, and religious differences. Different social events like, Mela, (annual ritualistic celebration and get together), Eid, celebration day and night tournaments of indigenous games and many other social, political, and economic events and rituals practiced in the village. All these events and get-together sittings give opportunities to heads of different clans and tribes to discuss and solve socioeconomic, political and religious issues. Similarly, it also provides a platform for socialization of young buddies about social moral values being a member life of society. In contrast to this, today people have adopted an individualistic style of living. One of the major drawbacks of this style is that members have lost the opportunities to socialize according to the demand of the society. Hence, they also lose the opportunity to enjoy social and political life being a member of the society. It affects the social balance, order, peace and harmony of the village".

\section{Famishment of wealth}

Competition to become rich is a dream of everyone's life. According to 35 years old key informant, "most people compromise to enjoy their social and family life in spending their energies to accumulate money and wealth in handsome amounts". Moreover, according to the research findings, persistent depression for a longer time period is significantly associated with low level of income. Such association is interacted by fair to poor status of health, stress and depression and low level of self-efficacy. The element of competition of being wealthy and rich was one of the major determinants of depression among people living in the village. People live with constant stress due to unsettled competition of being wealthy. Similarly, class systems based on economics are one of the major components in every next societal structure. It is an important factor for depression found 
among the people which provokes the sense to be at high rank in the society as to enjoy prestige and status. As a result, most people do not achieve said prestige and status and become frustrated. It is one of the common factors for depression found among the people living in the village.

\section{Economic hardship}

Economic resources are general tools through which social situations are formed and that create diseases and health disparities. Economic institutions, business activities and political decisions affect who gets disease and access to health resources and actively produce disease and other risks. Social environment (pesticides and industrial pollutants) position of building factories near to poor communities. Further, misuse of deprived (low salaries, no health benefits) and political stance about funding public health and health care services. Culture and social environment have also important effects on health through stress and depressive disorder. People living in the village have an economic system which is directly related to conflicts. Tribal and other conflicts lead people to buy advanced and very costly weapons. People living in the village invest a lot of money in one way or other way in the quest of safeguarding and as to win the battle. According to one of the key informants, financial instability is one of the main causes of depression among people. However, those people who have good and enough financial resources are known as well ranked members of society and culture. Similarly, they have innate financial resources and social prestige. Apart from tribal conflict, that class of people enjoy their psychosocial, physical, and balanced happy life in the village".

According to research findings most of the people living in the village are dependent on agriculture for economic survival, which is seasonal and therefore people are supposed to face economic hardship in the few months of the year. In addition, the agriculture sector has dramatically changed with advancement, intervention and adaptation of modern technology related to agriculture. As a result, this sector does not meet economic demands for survival. However, it is difficult to live a life below the poverty level in any society. In the village, economic instability is causing depression among people as they compromise to live a happy life. People are used to working hard and engage themselves for extra hours of their duties for the sack to earn money. This condition creates physical exploitation of poor people which also reduces their physical capacities to work in their rest of the life to meet their family financial needs. That's how people compromise their happy lives by engaging themselves in working extra hours. According to current research observations, it is common that people who have low levels of earning resources are at more risk to be depressed.
Economic instability is one of the major variables which is associated with depression and vice-versa in research locale.

\section{Conclusion}

We can conclude that the economic structure of society, family relationships, health care facilities, cultural orientation and socialization are key for the health of an individual. However, many people in the village do not take depression as a disease and become habitual to live with the disease. One of the major reasons for ignorance of the disease is stigmatization of the disease with madness. Moreover, another reason is unavailability of trained psychiatrists and quality mental health hospitals in the village and the district. There is a dire need of mental health care consultants and hospital facilities for people living in the village. Beside this, social stigma or misperception associated with depression contentiously poses threats to a proper socio-psychological and mental treatment. Due to stigmatization related to mental health treatment, people who are in need of treatment do not bother to have consultation with trained health care practitioners. Hence, such people who need proper attention are living in worse health conditions. Moreover, culture and health cannot be studied in isolation to one another. Similarly, it is the culture which plays an important role to shape and develop habits, norms, values, customs, and traditions.

These cultural factorsare responsible for mental health and well-being. Beside this, social interaction, family structure, economic instability, social conflicts, and religious differences are key factors which pose a threat of depression among people. Social conflicts, in and outside the family generate factors of depression. Some families in the village are opponents to one another for many years. It is one of the major reasons that contributes and constructs depression among the people. For instance, huge amounts of money and human resources are used to show dominance over one another. This family rivalry results in the separation of family members that again pushes people to dark zones. In some serious cases, family rivalry results in the loss of many people and gives birth to a collective wave of tension and depression among the people who are part of it. This wave of depression adheres people to live their lives unhappy and depressed. It is agreed by most respondents living in the village that social conflicts pose an unpleasant social environment for people to enjoy their lives.

Property inheritance is an ascribed status, which a person receives from their ancestors. Sometimes it brings a lot of confusion in family relations due to alleged unfair division of land and resources. Number of families in the village fight for property inheritance. It is one among other social determinants of depression. Along with this, 
changes in the moral life of people have posed serious threats in giving birth to depression among people living in the village. Hence, it is important to think wisely before adopting any new change in one's life. People living in the village have changed drastically from abidance and obedience to deviant activities. Initially, people were used to live in social harmony, peace, tolerance and show respect to one another. The respondents, particularly mentioned in the interviews that the traditional attributes like harmony and tolerance to one another and previously adopted simple life patterns helped the people to live a calm and happy life.

\section{Bibliography}

Abdullah, A. (2009). The people and the land of Sindh: Historical perspective. Karachi, Sindh, Pakistan: Tanzeem Publishers.

Abas, M. A. \& Broadhead, J. C. (1997). Depression and anxiety among women in an urban setting in Zimbabwe. Psychological Medicine 27, 59-71.

Allan V. Horwitz, J. C. (2007). The Loss of Sadness: How Psychiatry Transformed Normal Sorrow into depressive disorder. New York: Oxford University Press.

Barnard, A. (2004). History and Theory in Anthropology. New York: Cambridge University Press.

Bernard, H. R. (2006). Research Methods in Anthropology (4rth ed.). New York: Alta Mira Press.

Borgatta Edgar F. and Montgomery Rhonda J. V. (2000). Encyclopedia of Sociology (Second ed., Vol. 1). New York, USA: New York, USA: Macmillan Reference USA an imprint of The Gale Group.

Ellen, R. (1984). Ethnographic Research: A guide to general conduct. London, New York, Boston, Tokyo, Sydney Toronto: Academic Press INC San Diego, CA 92101.

Emmanuel Akyeampong, Allan Hill, Arthur Klienman. (2015). The Culture of Mental Illness and Psychiatric Practice. Bloomington: Indiana University Press, Bloomington and Indian apolis.

Erickson, M. Singer, Merrill. (2011). A Companion to Medical Anthropology. West Sussex, UK: Blackwell Publishing Ltd.

G.Myers, D. (1993). Social Psychology (4rth ed.). New York, USA: McGRAW-HILL, INC.

Geissler, $\quad$ R. $\quad$ P. MedicalAnthropology.London: Bell and Bain Ltd, Glasgow.

Hans A. Bear, M. S. (2008). Medical Anthropology and the World System. 27(1), 4.
Haran, N. M. (2009). Cognitive Behavioral Therapy for Depression. Isr J Psychiatry Relat Sci Vol 46 No. 4, pp. 269-273.

Heatherton, M. S. (2006-2003). psychological Science (2nd ed.). New York, USA: W.W. Norton and Company, Inc.

Hollifield, M., Katon, W., Spain, D. \& Pule, L. (1990). Anxiety and depression in a village in Lesotho, Africa: A comparison with the United States. British Journal of Psychiatry 156, 343-350.

Hofgastein, B. (7 October 2011). "Designing the road to better health and Well-being in Europe" at the European Health FourmGastein. Austria: World Health Organization. Retrieved from file:///c:/Users/Anthro\%20Lab/Downloads /Documents/RD_Dastein_speech_wellbei ng_07Oct.pdf

Karp, D. A. (1994). The Dialectics of Depression. Wiley on behalf of the Society for the Study of Symbolic Interaction, 17(4), 346. Retrieved from https://doi.org/10.1525/si. 1994. 17.4 .341

Kleinman, A. (1981). Normal and abnormal behavior in Chinese culture. D. Reidel Publishing company Dordrecht: Holland/ Boston: USA: London: England

Kleinman, A. (2011). Deep China: The Moral Life of the Person, what anthropology and psychiatry. London, England: University of California Press, Ltd.

Koen, B. D. (2006). Musical Healing in Eastern Tajikistan: Transforming Stress and Depression through Falak performance.Asian Music, vol.37, No. 2, 58-83.

Lee, S. (2011). Depression Coming of Age in China. Los Angeles, California: Regents of the University of California.

Lewis, B. (2012). Depression: Integrating Science, Culture, and Humanities. New York \& UK, United Kingdom and United States of America: Routledge, 2 Park Square, Milton Park, Abingdon, Oxon OX14 4RN.

linzdzey, G. (1975). Psychology. New York, USA: Worth Publisher, INC.

Mar, D. (1972, December). Textbooks and Readers: Anthropology Today. 366-67. Retrieved on $10^{\text {th }}$ November, 2018, from https://doi.org/10. 1525/aa. 1972.74.6.02a00190

Malik, H. Gankovsky, Yuri. V. (March 2006). The encyclopedia of Pakistan (1st Printing edition ed.) Karachi, Pakistan: Oxford University Press.

Murphy, R. F. (1989). Cultural and Social Anthropology an Overture (Third ed.). New Jersey: Prentice-Hall, Inc. 
Paing, K. Y. (Jun 1994). Understanding Depression among Elderly Korean Emigrants Through their Folk Illness. Medical Anthropology Quarterly, Vol.8, No. 2, 209-216.

Population Census Organization Statics Division Government of Pakistan, I. (1998). 1998 District Census Report of Larkana. Islamabad: Population Census Organization Statics Division Government of Pakistan, Islamabad. Retrieved November 2, 2018, from http://hdl.handle.net/123456789/14673

Qamar, A. H. (2016, 8 13). Belief in the Evil Eye and Early Childcare in Rural Punjab, Pakistan. Asian Ethnology, 75, 413. Retrieved 8.13.2018, from https://www.jstor.org/stable/asianeth.75.2. 397

Robert A. Baron, N. R. (2009). Social Psychology (12 ed.). New Delhi: Dorling Kinder Fley (India) Pvt. Ltd.

Rogers, K. (2017, November 20). Stress: Psychology and Biology. The Editors of Encyclopedia Britannica, 1-3. Retrieved July 5th, 2018, from https://www.britannica.com

Rogers, K. (2019). Depression. The Editors of Encyclopedia Britannica, 1-2. Retrieved on $12^{\text {th }}$ December 2018, from https://www.britannica.com/science/depre ssion -psychology

Ross, C. E. (Dec., 1985). Hardship and Depression. Journal of Health and Social Behavior, Vol. 26 No. 4 pp 312-327.
Rouse, P. (April, 1991). Teaching an Interdisciplinary Course in Social Psychology. Teaching Sociology, Vol. 19 No. 2, 164-172.

Roy Moodley, Patsy Sutherland and Olga Oulanova. (2008). Counselling Psychology Quarterly.Routledge Taylor \&Francis Group, Vol. 21, No. 2, June 2008, 153-165, 154.

Rumberger, Russell W. Ghatak, R. Poulos, G. Ritter, Philip, 1. Dornbusch, M. Sanford. (Oct., 1990). Family Influences on Dropout Behavior in One California High School. American Sociological Association, Vol. 63 No. 4, 283-299.

Sluka, A. C. (2007). Ethnographic Fieldwork: An Anthropological Reader (Vol. 9). Victoria: Blackwell.

Trostle, J. A. (2005). Epidemiology and Culture. New York, USA: (C) Cambridge University Press.

Warms, N. (2007). Cultural Anthropology (9 ed.). USA: Thomson Learning, Inc.

WHO (22 March 2018). Depression. Geneva, Switzerland: WHO. Retrieved on $15^{\text {th }}$ November 2019, from https://www.who.int/news-room/factsheets/detail/depression

Winkelman, M. (2009). Culture and Health: Applying Medical Anthropology (1st ed.). New York, USA: Jossey/ Bass, p. 38.

WHO \& World Bank (1996). The Global Burden of Disease. (ed. C. J. L. Murray and A. D. Lopez). Published by the Harvard School of Public Health on behalf of the World Health Organization and the World Bank: Cambridge, $\mathrm{M}$. 